\title{
Influence of Cultural Factors on Choice of Childbirth Place Among Women in Oyigbo Local Government Area, Rivers State, Nigeria
}

NGOZI AFULENU OBIKA-NDIRI

https://orcid.org/0000-0002-4564-4630

CHIZOMA MILLICENT NDIKOM

OGOCHUKWU IMMACULATE OBIKA ( $\square$ obika.immaculate@gmail.com )

https://orcid.org/0000-0002-2571-8479

OMINEOKUMA TUBONEMI ASEMINASO

\section{Research Article}

Keywords: Birthplace, Childbirth, Maternal Mortality, Oyigbo, Women's health

Posted Date: January 23rd, 2023

DOI: https://doi.org/10.21203/rs.3.rs-1093346/v2

License: (c) (i) This work is licensed under a Creative Commons Attribution 4.0 International License.

Read Full License

Version of Record: A version of this preprint was published at INTERNATIONAL JOURNAL OF NURSING AND MIDWIFERY SCIENCE (IJNMS) on January 10th, 2023. See the published version at https://doi.org/10.29082/IJNMS/2022/Vol6/lss3/400. 


\section{Abstract}

BACKGROUND: Some cultural practices which encourages both maternal mortality and infant death, are still a major challenge especially in developing countries like Nigeria, cultural norms and practices during childbirth are common but little is documented about how these cultural and religious beliefs influence women and their childbirth place choices. The aim of this study was to find out the prevalent cultural factors that influence the choice of childbirth places among the women of child bearing age, in Oyigbo Local Government area of Rivers State in Nigeria.

METHODOLOGY: A self-structured questionnaire was used as instrument to collect data for the study through simple random sampling, and these data was analyzed using Frequency and percentage for descriptive statistics while chi-square was used for inferential statistics at 0.05 level of significance.

RESULT: The result showed that most of the women had secondary education and were mostly influenced by patriarchal system, and also there was a high level of hospital adherence among the women in Oyigbo. The influence of cultural factors; family traditions $\left(x^{2}=12.56, P=0.006\right)$, religious beliefs $\left(x^{2}=70.66, P=0.000\right)$, Lack of confidence in health facilities $\left(x^{2}=367.83, P=0.000\right)$, and Presence of male skilled birth attendants $\left(x^{2}=50.85, P=0.000\right)$, were statistical significant to the choice of childbirth place while patriarchal system $\left(x^{2}=2.99, P=0.393\right)$ was not statistically significant to the choices of childbirth places of women in Oyigbo. Influence of religion $\left(x^{2}=125.46, P=0.000\right)$ on choices childbirth place was statistically significant.

CONCLUSION: Therefore, this study has shown that there is significant religious and cultural influence on the choices of childbirth places of women in Oyigbo Local Government Area of Rivers State.

\section{Introduction}

Nigeria like many other countries in sub-Saharan Africa, has long been overwhelmed with maternal health challenges. Maternal health improvement has attracted global attention and improving women's health issues pertaining to pregnancy and delivery has become the centerpiece of national development efforts in developing countries. However, despite the relentless effort, there is little evidence to show significant decline in maternal mortality ${ }^{1}$. The child birth mortality rate has increased in Nigeria and statistics has suggested that 144 women die each day in Nigeria due to pregnancy related reasons, which suggests that the country is one of the worst countries for handling childbirth processes ${ }^{2}$. Some of the factors that determine maternal mortality include: accessibility to health services, cultural practices, socio-economic status, and the educational background of the child bearing women. In Nigeria, one of the commonest childbirth practices is home births and this is highly influenced by the community and culture ${ }^{3}$. Home births usually occur in many resource-poor countries as evident in the study by Sabit et al. showing that Ethiopia recorded many home births, which is an indicator that home births were still a common practice ${ }^{4}$. Home births can be planned or unplanned. A planned home birth is not often associated with maternal or prenatal mortality ${ }^{5}$. The existence of various customs and traditions in Nigeria has also 
affected the maternal and child health. Nigeria has about 374 ethnic groups, with each ethnic group practicing different cultures which mostly affects childbirth in the country. There is a chance of 1 in every 13 women to die of pregnancy-related causes in Nigeria. These maternal deaths occur during labor, child delivery or within first 24 hours after childbirth ${ }^{6}$. The deaths that occur after childbirth are often caused by avoidable causes. Situations like infections, sepsis, eclampsia and hemorrhage after childbirth can be easily prevented in a functional healthcare system ${ }^{7}$.

Cultural beliefs, norms, values, and traditions have a major influence on decision making whether a mother seeks skilled delivery care or not ${ }^{8}$. Traditional beliefs and practices, religion and ethnicity influences greatly on cultural practices that power choice of women place of giving birth ${ }^{9}$. Some cultural beliefs are interlinked with religious beliefs ${ }^{10}$. Most African women consider the right to good health as contingent on fulfilling their purpose of taking care of and meeting the needs of their families especially, the husband, at the expense of their own physical health and well-being ${ }^{1}$. There is a religious and cultural dimension for this consideration such as the African traditional religion and an Islamic culture patriarchal system that undervalues women by putting women's reproductive health capacities under strict male control, the practice of wife seclusion which restrict women's medical care, marriage at an early age leading to pregnancy often occurring before maternal pelvic development is complete, polygamy and harmful traditional medical practices ${ }^{1}$.

Female autonomy; which is the ability of a woman to make decisions in the family relative to the man, plays a vital role in maternal health care. In most African countries, the husbands make a choice of where the wives should deliver ${ }^{11,12}$ and maternal age of women is a determining factor to how the women of child bearing age indulge in childbirth practices ${ }^{13}$. In some cultures, women are often given off to marriage before they get to the expected maturity age of eighteen which is still obtainable Gombe, Adamawa State in Nigeria, and such cultural practices are known to have encouraged girl child marriage ${ }^{14}$, which in turn decreases their chance of autonomy as women are expected to get to a particular age so as to be considered old enough for marriage. In this way, only women who are older are more confident and influential in making their own decisions when in marriage as compared to younger women. Hence, they can choose childbirth practices that are favorable to them.

Some cultural factors can be of negative influence on childbirth place choices in a community and has played a major role to childbirth attitudes among pregnant women. For instance, some taboos and practices that prevent women from taking appropriate decision on where and when to seek medical attention during pregnancy and childbirth are harmful ${ }^{15}$. In addition, the use of Caesarian section during childbirths is being avoided by some women due to cultural beliefs. Albeit Caesarian section is often carried out to assist pregnant women who could not push the baby out from the vagina, it is in contrast with the normal vaginal birth. Therefore, some pregnant women refuse Caesarian section even when they clearly need it while in labor because their cultural beliefs is averse towards the procedure ${ }^{16}$. 
Tribalism and ethnicism is a huge factor influencing many practices in sub-Saharan Africa. Many countries in Africa have regions that speak different languages and also practice different cultures ${ }^{17}$. Because of this, these individuals tend to discriminate among themselves in such a way that women of child bearing age, are selective in the hospitals they are bound to attend. Some of these women may decide not to visit the hospitals for medical care because they do not want to interact with individuals from a different tribe. Some culture also enforces individuals to adopt the traditional religion which has been practiced by their ancestors. Almost all tribes in Nigeria still have individuals who practice traditional religion and these individuals often reject western development. And these people who practice traditional religion do not usually belief in medical services and would resort to the use of traditional herbs for handling pregnancy related conditions ${ }^{10}$. Even amidst the pressure to abolish religious-based healthcare and traditional healing rituals, it has gained fresh momentum especially in Nigeria ${ }^{18}$.

In other cases, some cultural and religious beliefs do not allow child bearing women to receive treatments from male professionals ${ }^{10}$. Tanzanian women of shy away from hospital delivery because they perceive vaginal examinations as painful and that it is dehumanizing for a male healthcare provider to perform a vaginal examination, and this makes most of the women to choose other deliveries place where all birth attendants are certainly women ${ }^{12}$. The cultural background of most women of child bearing age in Northern Nigeria has made them reject medical care offered by male professionals ${ }^{16}$. The women are forbidden from allowing another man, who is not their husbands to see their nakedness in accordance to the laws of Islam ${ }^{12}$. Hence, these women fear to get registered for ante-natal care or hospital births because they do not want to be presented with the situation where male health care professionals would examine them during their pregnancy. As evident with Hausa women of Kaduna State, who were not comfortable with male doctors/nurses attending to them in hospitals in the study by Okeshola and Sadiq ${ }^{3}$.

Also discrimination based on religious factor affects the maternal health care of women from different backgrounds ${ }^{19}$. The emergence of African independent church movements has revived interest in religion and spiritual Healthcare ${ }^{18}$. Religious leaders often back up childbirth with spiritual reasons. They provide birth rooms and promise good delivery outcomes derived from divine/supernatural involvement. Hence, these women end up not seeking for skilled health care professionals during pregnancy since they believe more in supernatural healthcare and prayer house delivery 3,18 .

Diversity in childbirth is a global phenomenon. Cultural diversity in Nigeria has led to the numerous differences among people in terms of ideologies, values, principles, morals and standards ${ }^{20}$. Having a good knowledge of the existing cultures applicable to a particular environment is a key to ensuring low maternal mortality rates and ensuring safe childbirth practices in the country. Nigeria comprises of 774 local government areas and about 250 dialects are spoken across these local governments. Each local government is dominated by different ethnic groups with their various cultural beliefs. In most cases, 
cultural beliefs are interlinked with religious beliefs and they influence choice of childbirth places in these areas $^{21}$. The women of childbearing age in Oyigbo Local Government need to be conversant with these cultural practices or beliefs existing in the regions where they reside or visit, and be aware of safe and unsafe childbirth places involved which would enable them to make an early and planned decision of place of childbirth. These women should be aware that the availability of healthcare professionals during childbirth is an important factor in preventing maternal mortality and align with the Millennium Development Goal of improving maternal health ${ }^{16}$. It is also important that healthcare professionals are aware of these cultural practices in these regions and how they affect women should be put into consideration $^{10}$. Therefore, this study is aimed to explore the significance of the influence of some cultural factors on choices of childbirth places among women in Oyigbo local government area of Rivers State, Nigeria.

\section{Materials And Methods}

\section{Study Design and Area}

The research is a quantitative type of design which is descriptive and a cross-sectional research study approach which involves collecting, analyzing and interpreting data collected through questionnaire.

The study was conducted in Oyigbo Local government which is one of the 23 local governments of Rivers State of the South-South geopolitical zone of Nigeria. It's headquarter is in a town known as Afam, with an estimated population of about $209,841^{22}$. Oyigbo is made up of towns, villages and districts. The area hosts members of the Oyigbo sub-division of the Igbo ethnic group and dominated by Igbos. The language commonly spoken in the local government is the Obigbo dialect with Aanang and English language also spoken in the area. The practice of Christianity and traditionalism dominates the towns within the local government. The traditional ruler in the local government is known as the Eze of Oyigbo. There are notable festivals held in the area with the most popular one as the Ekpe masquerade festival ${ }^{22}$.

\section{Sample}

The study population was women of childbearing age in Oyigbo Local Government Area. The study units were women of childbearing age in Oyigbo Local Government Area that entered St. Paul's Catholic Church Health Post during the study period. The sampling strategy employed was random sampling.

The inclusion criteria were women from 20-60years with at least one record of childbirth who are resident in Oyigbo and the exclusion criteria were women who were judged by the researcher to be mentally unstable and who refused to give consent or complete the survey because they were morbidly ill or afraid of losing their privacy.

The sample size was calculated as 384 using the Fischer's single population formula $\mathbf{n}=\left(\mathbf{Z}^{2} \mathbf{x} \mathbf{p} \mathbf{x}\right.$ $\mathbf{q}) / \mathbf{d}^{2}$ according to Charan and Biswas ${ }^{23}$; where $\mathbf{Z}$ is the normal variable associated with significance 
level a (1.96), $\mathbf{p}$ is Proportion of the population with the desired characteristic (stated as $50 \%{ }^{24}$ ), $\mathbf{q}=1-p, \mathbf{d}$ is the required level of precision/discrepancy $(5 \%=0.05) . \mathbf{n}=\left[1.96^{2} \times 0.5 \times(1-0.5)\right] / 0.05^{2}=\mathbf{3 8 4}$

\section{Instrument}

The questionnaire was developed in English as the instrument for the research after a thorough review of literature on cultural factors that influence choice of childbirth place in similar settings. The questionnaire elicited information about Demographic data, Common childbirth places and of the respondents, and cultural factors influencing choice of childbirth places in three sections. The sections had two types of question: those for which only one answer could be given and those for which more than one answer was possible. The questionnaire was structured and consisted of close ended questions, measured using categorical variables scale. The instrument was pilot tested on a small sample of respondents for usability and feasibility. The questionnaire was self administered but for unlearned women the questionnaire was interviewer administered and interpreted into local languages.

The reliability of the instrument was determined through the test-retest method. To ascertain the reliability co-efficient, 10 copies of the instrument were administered to a sample of 10 randomly selected women of childbearing age in Oyigbo Local Government Area of Rivers State, to respond to the items presented and the instruments were retrieved for analysis. The same copy of instrument was given to the same sample after two weeks of the initial one. The initial and final analysis was correlated and the reliability co-efficient was 0.81 .

To ensure validity of the instrument, it was given to the research supervisor and other consultants in public health and community medicine for corrections and proper adjustments.

The instrument was forward translated into local languages by native speakers and translation reviewed by the researchers, midwifery and public health experts. The translation was pilot tested on a small sample of respondents for comprehensibility by asking what they think the questions and corresponding responses mean.

\section{Data Collection}

The study was conducted in St. Paul's Catholic Church Health Post Oyigbo in January - March 2020. Data was collected by the health team at working hours. The data collection process was closely supervised by the principal investigator and researchers. The data collectors were recruited based on previous experience on data collection and fluency in the local language. The data collectors and supervisors were trained on interviewing, handling ethical issues and maintaining confidentiality and privacy.

\section{Data Analysis}

Data was analyzed using the Statistical Package for Social Sciences (SPSS) Version 22 (SPSS Inc., Chicago, IL., USA). Descriptive data analysis uses frequency distribution and Chi-square technique was 
used to test the hypotheses, with level of significance set as $p<0.05$.

\section{Ethical Consideration}

The research subjects were thoroughly informed of the objectives of the study and of their right to opt out of the study at any point when they feel the need to do so, and they provided their written informed consent. The research received ethical approval from research ethics committee of the University of PortHarcourt UPH/CEREMAD/REC/MM68/025 on 20 December 2019. Acceptance and permission to conduct the research in Oyigbo was granted by His Royal Highness Eze Mike Nwaji JP on April 2020.

\section{Results}

Analysis of Demographic Data

Table 1: Socio-demographic Characteristics of the Respondents

\begin{tabular}{|c|c|c|}
\hline Demography & Frequency $(\mathrm{n}=$ & Foutcent \\
\hline \multicolumn{3}{|l|}{ Age } \\
\hline $20-25 y r s$ & 65 & 16.9 \\
\hline $26-31 y r s$ & 198 & 51.6 \\
\hline $32-37 y r s$ & 99 & 25.8 \\
\hline 45yrs \& above & 22 & 5.7 \\
\hline \multicolumn{3}{|l|}{ Educational Level } \\
\hline No Formal Education & 22 & 5.7 \\
\hline Primary Education & 11 & 2.9 \\
\hline Secondary Education & 219 & 57.1 \\
\hline Tertiary Education & 110 & 28.6 \\
\hline Post-Graduate Education & 22 & 5.7 \\
\hline \multicolumn{3}{|l|}{ Marital Status } \\
\hline Married & 351 & 91.4 \\
\hline Single & 22 & 5.7 \\
\hline Separated & 11 & 2.9 \\
\hline \multicolumn{3}{|l|}{ Religion } \\
\hline African Traditional Religion & 26 & 6.8 \\
\hline Christian & 258 & 67.2 \\
\hline Muslim & 64 & 16.7 \\
\hline Others & 36 & 9.4 \\
\hline \multicolumn{3}{|l|}{ Income } \\
\hline$<\# 30,000$ & 263 & 68.5 \\
\hline$\$ 30,000-¥ 79,999$ & 66 & 17.2 \\
\hline$\$ 80,000-\$ 149,999$ & 22 & 5.7 \\
\hline$\$ 150,000-\$ 349,999$ & 22 & 5.7 \\
\hline$\$ 350,000 \&$ above & 11 & 2.9 \\
\hline \multicolumn{3}{|l|}{ Occupation } \\
\hline Public Civil Servants & 33 & 8.6 \\
\hline Private Civil Servants & 77 & 20.1 \\
\hline Business/Traders & 230 & 59.9 \\
\hline Others & 44 & 11.4 \\
\hline
\end{tabular}

Common choices of childbirth place among the women in Oyigbo 
Table 2: Choice of childbirth place among the women of childbearing age

\begin{tabular}{|l|r|r|r|r|}
\hline \multirow{2}{*}{ CHILDBIRTH PLACE } & \multicolumn{2}{|c|}{ YES } & \multicolumn{2}{c|}{ NO } \\
\cline { 2 - 5 } & Frequency & Percent \% & Frequency & Percent \% \\
\hline Hospital & 351 & 91.41 & 33 & 8.59 \\
\hline Traditional Birth Attendant Homes & 19 & 4.95 & 365 & 95.05 \\
\hline Home delivery & 9 & 2.34 & 375 & 97.66 \\
\hline Others & 5 & 1.30 & 379 & 98.70 \\
\hline
\end{tabular}

YES: represents number of respondents that chose the childbirth place.

NO: represents number of respondents that did not choose the childbirth place.

Cultural factors influencing the choice of childbirth place among the women in Oyigbo

Table 3: Cultural factors affecting the women's choice of childbirth places in Oyigbo L.G.A

\begin{tabular}{|l|l|l|l|l|}
\hline CULTURAL FACTORS & YES & NO & \\
\cline { 2 - 5 } & Frequency & $\begin{array}{l}\text { Percent } \\
\%\end{array}$ & Frequency & $\begin{array}{l}\text { Percent } \\
\%\end{array}$ \\
\hline Family traditions & 37 & 9.64 & 347 & 90.37 \\
\hline Religious beliefs & 32 & 8.33 & 352 & 91.67 \\
\hline Lack of confidence in health facilities & 31 & 8.1 & 353 & 91.9 \\
\hline $\begin{array}{l}\text { Presence of male skilled birth } \\
\text { attendants }\end{array}$ & 134 & 34.9 & 250 & 65.1 \\
\hline Patriarchal system & 212 & 55.21 & 172 & 44.79 \\
\hline
\end{tabular}

YES: respondents affected by factor. NO: respondents not affected by factor.

\section{Significance of the influence of Cultural factors on the women's choices of childbirth place}

Table 4 shows the changes in the way the variables are distributed into categories. The null and the alternate hypothesis are as stated below;

$\mathrm{H}=$ There is no significant association between cultural factors and choices of childbirth places among the women

$\mathrm{H}=$ There is significant association between cultural factors and choices of childbirth places among the women

Table 4: Extent to which cultural factors affect the women's choices of childbirth places 


\begin{tabular}{|c|c|c|c|c|c|c|c|c|}
\hline \multirow{2}{*}{\multicolumn{2}{|c|}{ Cultural Factors }} & \multicolumn{4}{|c|}{ Childbirth Place } & \multirow{2}{*}{$\mathrm{X}^{2}$} & \multirow{2}{*}{ df } & \multirow{2}{*}{$\begin{array}{l}\mathrm{P}- \\
\text { value }\end{array}$} \\
\hline & & HOSPITAL & TBA & Home & Others & & & \\
\hline \multirow[t]{2}{*}{ Family traditions } & $\overline{\mathrm{YES}}$ & 30 & 6 & 0 & 1 & \multirow[t]{2}{*}{12.56} & \multirow[t]{2}{*}{3} & \multirow[t]{2}{*}{0.006} \\
\hline & $\mathrm{NO}$ & 321 & 13 & 9 & 4 & & & \\
\hline \multirow[t]{2}{*}{ Religious beliefs } & YES & 17 & 9 & 5 & 1 & \multirow[t]{2}{*}{70.66} & \multirow[t]{2}{*}{3} & \multirow[t]{2}{*}{0.000} \\
\hline & NO & 334 & 10 & 4 & 4 & & & \\
\hline \multirow{2}{*}{$\begin{array}{c}\text { Lack of confidence in health } \\
\text { facilities }\end{array}$} & $\overline{Y E S}$ & 0 & 19 & 9 & 3 & \multirow[t]{2}{*}{367.83} & \multirow[t]{2}{*}{3} & \multirow[t]{2}{*}{0.000} \\
\hline & $\mathrm{NO}$ & 351 & 0 & 0 & 2 & & & \\
\hline \multirow{2}{*}{$\begin{array}{c}\text { Presence of male skilled birth } \\
\text { attendants }\end{array}$} & $\overline{\mathrm{YES}}$ & 104 & 18 & 7 & 5 & \multirow[t]{2}{*}{50.85} & \multirow[t]{2}{*}{3} & \multirow[t]{2}{*}{0.000} \\
\hline & $\mathrm{NO}$ & 247 & 1 & 2 & 0 & & & \\
\hline \multirow[t]{2}{*}{ Patriarchal system } & YES & 194 & 12 & 5 & 1 & \multirow[t]{2}{*}{2.99} & \multirow[t]{2}{*}{3} & \multirow[t]{2}{*}{0.393} \\
\hline & $\mathrm{NO}$ & 157 & 7 & 4 & 4 & & & \\
\hline
\end{tabular}

The table revealed that the $d f=3$ and $P>0.05$. If obtained $p$ value is less than the level of significance 0.05 , the alternative hypothesis stating that there is significant association between cultural factors and choice of childbirth places is accepted and vice versa.

\section{Significance of the religious beliefs on the women's choices of childbirth place in Oyigbo}

Table 5 showed the observed count revealing the way the variables are distributed into categories. The null and the alternate hypothesis as stated below;

$\mathrm{H}=$ There is no significant association between religious beliefs and choices of childbirth places among the women

$\mathrm{H}=$ There is significant association between religious beliefs and choices of childbirth places among the women

Table 5: Association between the levels of religion and choice of birth place

\begin{tabular}{|c|c|c|c|c|c|c|c|}
\hline \multirow[b]{2}{*}{ RELIGION } & \multicolumn{4}{|c|}{ CHILDBIRTH PLACE } & \multirow[t]{2}{*}{$\mathrm{X}^{2}$} & \multirow{2}{*}{\multicolumn{2}{|c|}{ df P-value }} \\
\hline & HOSPITAL & TBA & HOME & OTHERS & & & \\
\hline African Traditional Religion & 11 & 12 & 3 & 0 & 125.46 & 9 & 0.000 \\
\hline Christian & 252 & 1 & 3 & 2 & & & \\
\hline Muslim & 55 & 4 & 2 & 1 & & & \\
\hline Others & 32 & 2 & 1 & 2 & & & \\
\hline
\end{tabular}

The ${ }^{2} \mathrm{cal}$ is 125.46 with $d \mathrm{f}=9$ and $P<0.05$. The obtained $p$-value of 0.000 is less than 0.05 . Therefore the null hypothesis is rejected. This indicates that there is a significant association between the religious 
beliefs and choices of childbirth places among the women of childbearing age in Oyigbo Local Government Area of Rivers State.

\section{Discussion}

From the findings of the study as revealed in Table 1, a high percentage (91.4\%) of the respondents preferred hospital as childbirth place than traditional birth attendant homes, home delivery and others. This implies that the respondents are aware of the presence of skilled medical professionals in hospitals which is the assurance of their safe delivery ${ }^{25}$. Other studies like Nigeria Demographic and Health Survey (NDHS) may have divergent opinion that majority of women of child bearing age, deliver at home ${ }^{26}$, but unlike the northern part of Nigeria which has the highest number of records of such births ${ }^{16}$, the southern part of Nigeria is lower. This study suggest that women of childbearing age in Oyigbo are mostly Christians (67.2\%) who are more averse to traditional practices and promote hospital-based maternity care although some churches promotes prayer house delivery ${ }^{18}$.

In this study, more than half percentage (55.21\%) of respondents agrees to patriarchal system of the community affecting their choices of childbirth places as previously noted by Matseke et al. in their study on gender differences ${ }^{27}$. According to them, most African societies present males to dominate the females and this system has led to the concept of 'Patriarchy'. Hence, women do not have the right to decide where to deliver their babies. Only what the man says is what stands, whether it is in favor of the unborn child and mother or not ${ }^{27}$. In a related study by Aluko-Arowolo and Ademiluyi they noted that in Madagali which is located in North-Eastern Nigeria, a significant number of home births take place and are supervised by unskilled individuals approved by their husbands or the man responsible for the pregnancy ${ }^{28}$.

Findings from Table 4 revealed that there is association between cultural factors and choice of childbirth practices among the women of childbearing age in Oyigbo Local Government Area of Rivers State except for the factor Patriarchal system, and this agrees with Leslie and Gupta who indicated in their study that some cultural and religious beliefs do not allow childbearing women to receive treatments ${ }^{9}$ to which, any birthplace that is not vetted by the family tradition or that has male attendants as health workers is not considered proper for child delivery. However, because of the level of education and the background of most women in the area matters as some of them may come from enlightened homes ${ }^{16}$, even when the decision is solely on the man they still opt for medical care in hospitals for the safety of their children, therefore, Patriarchal system does not significantly affect their choices of childbirth place.

Findings from Table 5 revealed that there is significant association between religion and choice of childbirth practices among the women of childbearing age in Oyigbo Local Government Area of Rivers State and this agrees with Ababor et al. that suggests that cultural beliefs are interlinked with religious beliefs and people who practice traditional religion do not belief in some medical services, they will be averse to giving birth in the hospital as they cannot practice some birthing rituals ${ }^{10}$. And the use of 
traditional birth attendant and herbal drugs may continue to grow with the recent shift in focus towards traditional natural medicine ${ }^{29}$, if incorporation of cultural, traditional and religious care with medical care is not considered as an attracting force to utilization of hospital maternity services ${ }^{18}$.

\section{Conclusion}

Hospital is the preferred birthplace among the women in Oyigbo Local Government Area of Rivers State, this exposure could be attributed to the growing modernization, like; the autonomy, interethnic relation, level of education and societal status of the women and their family might cause them to choose the safest health care for both the mother and child. Religious belief and most of the cultural factors presented in this study influence the choices of childbirth places of women in Oyigbo significantly, therefore, provisions of safer accommodations for cultural and religious practices in the area, such as removing the male presence in the hospital on request.

\section{References}

1. Lowe M, Chen DR and Huang SL. Social and Cultural Factors Affecting Maternal Health in Rural Gambia: An Exploratory Qualitative Study. PLoS ONE. 2016; 11(9): e0163653. doi:10.1371/journal.pone.0163653

2. World Health Organization. Maternal mortality: WHO fact sheet on maternal mortality with key facts and providing information on MDG 4, where deaths occur, causes, lack of care and WHO response. World Health Organization Fact Sheet. Geneva. 2018.

3. Okeshola, FB and Sadiq, I. Determinants of Home Delivery among Hausa in Kaduna South Local Government Area of Kaduna State, Nigeria. Am. Int. J. Contemp. 2013; 3(5): 78-85.

4. Sabit, A, Zewdie, B, Atkure, D, et al. Socio-cultural Beliefs and Practices Influencing Institutional Delivery Service Utilization in Three Communities of Ethiopia: A Qualitative Study. Ethiop J Health Sci. 2019; 29(3): 343-52. http://dx.doi.org/10.4314/ ejhs.v29i3.6

5. National Population Commission (NPC). Nigerian Demographic and health survey 2008. National Population Commission and ICF Macro. Abuja, Nigeria. 2009.

6. Ali, TS, Fikree, FF, Rahbar, MH., et al. Frequency and determinants of vaginal infection in postpartum period: A cross sectional survey from low socioeconomic settlements, Karachi, Pakistan. J Pak Med Assoc. 2006; 56(3): 99-103.

7. Henderson, $J$ and Petrou, S. Economic implications of home births and birth centre: A structured review. Birth. 2008; 35(2): 136-46.

8. Gabrysch, $S$ and Campbell, OM. Still too far to walk: Literature review of the determinants of delivery service use. BMC Pregnancy Childbirth. 2009; 9(1): 34. Doi: 10.1186/1471-2393-9-34

9. Leslie J and Gupta GR. Utilization of Formal Services for Maternal Nutrition and Health Care. Washington DC, USA: International Center for Research on Women.1989. 
10. Ababor, S., Birhanu, Z., Defar, A., et al. Socio-cultural Beliefs and Practices Influencing Institutional Delivery Service Utilization in Three Communities of Ethiopia: A Qualitative Study. Ethiop. J. Health Sci. 2019; 29(3), 343-52. https://doi.org/10.4314/ejhs.v29i3.6

11. World Health Organization. Improved access to maternal health services. World Health Organization. Geneva. 2012.

12. Magoma, M, Requejo, J, Campbell, OM, et al. High ANC coverage and low skilled attendance in a rural Tanzanian district: a case for implementing a birth plan intervention. BMC Pregnancy Childbirth. 2010; 10: 13. https://doi.org/10.1186/1471-2393-10-13.

13. Burgard, S. Race and Pregnancy-related Care in Brazil and South Africa. Soc. Sci Med. 2004; 59: 1127-46.

14. Adedokun $\mathrm{O}$, Adeyemi $\mathrm{O}$ and Dauda $\mathrm{C}$. Child marriage and maternal risks among young mothers in Gombi, Adamawa State, Nigeria: implications for mortality, entitlements and freedoms. Afri health sci. 2016; 16(4): 986-99. Doi: 10.4314/ahs.v16i4.15

15. Ezeama, MC and Ezeamah, I. Attitude and socio-cultural practice during pregnancy among women in Akinyele L. G. A. of Oyo State, Nigeria. J. Res. Nurs. Midwifery. 2014; 3(1): 14-20.

16. Bukar M and Jauro YS. Home births and postnatal practices in madagali, North-Eastern Nigeria. Niger J Clin Pract. 2013; 16: 232-7.

17. Mbaya, N. Influence of social-cultural factors on women's preference for traditional birth attendants' services: A case Nakuru county, Kenya. [Master's thesis]. Nairobi, Kenya: University of Nairobi. 2017

18. Ohaja, M, Murphy-Lawless J and Dunlea M. Religion and Spirituality in Pregnancy and Birth: The Views of Birth Practitioners in Southeast Nigeria. Religions. 2019; 10: 82. doi:10.3390/rel10020082

19. Cockrill K., and Nack A. "I'm Not That Type of Person': Managing the Stigma of Having an Abortion." Deviant Behav.2013; 34(12): 973-90.

20. Esienumoh, EE, Akpabio, II, Etowa, JB et al. Cultural Diversity in Childbirth Practices in a Rural Community in Southern Nigeria. J Preg Child Health 2016; 3:

280. https://www.omicsonline.org/open-access/cultural-diversity-in-childbirth-practices-of-a-ruralcommunity-in-southernnigeria-2376-127X-1000280.php?aid=80286

21. Kaphle, S, Hancock, $\mathrm{H}$ and Newman, L. Childbirth traditions and cultural perceptions of safety in Nepal. Midwifery. 2013; 29: 1173-81. doi:10.1016/j.midw.2013.06.002.

22. Nwaji PO. "Peaceful Oyigbo". The Port Harcourt Telegraph. 2009. http://www.thephctelegraph.com/stories/July\%202009/2207news_07.html. Accessed 2 January 2020.

23. Charan, J, and Biswas, T. How to calculate sample size for different study designs in medical research? Indian J. Psychol. Med. 2013; 35(2): 121-6. https://doi.org/10.4103/0253-7176.116232

24. Feyisetan B., Fikree F., Saad A., et al. Summary Report of the Pre-intervention Health Facility Assessment of Emergency Obstetric Care in Cross River State, Nigeria: The Saving Mothers, Giving Life Initiative. Washington, DC. USA Evidence to Action Project, USAID. 2017. 
https://www.pathfinder.org/wp-content/uploads/2021/05/Nigeria-SMGL-Assessment-of-EmergencyObstetric-Care-REPORT.pdf

25. Ugwu, NU and de Kok, B. Socio-cultural factors, gender roles and religious ideologies contributing to Caesarian-section refusal in Nigeria. Reprod. Health. 2015; 12(70): 1-13. DOI: 10.1186/s12978-0150050-7

26. Nigeria Demographic and Health Survey (NDHS).Preliminary Report. National Population Commission.Federal Republic of Nigeria, Abuja. 2018.

27. Matseke MG, Ruiter RAC, Barylski N, et al. A Qualitative Exploration of the Meaning and Understanding of Male Partner Involvement in Pregnancy-Related Care among men in rural South Africa. J Soc Behav Health Sci. 2017; 11. Accessed from: https://scholarworks. waldenu.edu/cgi/viewcontent.cgi?article=1269\&context=jsbhs

28. Aluko-Arowolo SO and Ademiluyi, IA. Understanding Maternal Health in the Context of culture, Infrastructure and Development in Pluralististic Nigerian Society. Int. J. humanit. soc. sci.. 2015; 5(4): 151-8.

29. Obika OI and Ochekwu EB. Evaluation of Iron Concentration of Five Nigerian Shrubs for their Prospective use in the Therapy of Iron Deficiency Anemia (IDA). J. Nutr. 2021; 7(1): 1-7. DOI: 10.18488/journal.87.2021.71.1.7 